\title{
Awareness and Knowledge of Cancer: A Community Survey in Kedah and Perlis
}

\author{
Narimah Samat ${ }^{1,2}$, Suriati Ghazali ${ }^{1} \&$ Colonius Atang ${ }^{1}$ \\ ${ }^{1}$ School of Humanities, Universiti Sains Malaysia, Penang, Malaysia \\ ${ }^{2}$ Faculty of Arts and Social Sciences, Universiti Brunei Darussalam, Negara Brunei Darussalam \\ Correspondence: Narimah Samat, School of Humanities, Universiti Sains Malaysia, 11800 Penang, Malaysia. \\ Tel: 604-653-2854. E-mail: narimah@usm.my
}

Received: March 28, $2014 \quad$ Accepted: June 12, $2014 \quad$ Online Published: October 30, 2014
doi:10.5539/ass.v10n21p10
URL: http://dx.doi.org/10.5539/ass.v10n21p10

\begin{abstract}
Cancer is one the leading causes of death in developed countries and the second leading cause of death in developing countries. Awareness and knowledge of the danger of cancer and the need for cancer screening and early detection can reduce the risk of cancer-related deaths. This study examines the level of awareness and knowledge of cancer, cancer risk factors and the need for cancer screening among the general public in the states of Kedah and Perlis. This study also examines the relationship between residential location and education level and the awareness and knowledge of cancer. Findings from 544 respondents from urban, suburban and rural areas in Kedah and Perlis showed that even though a high percentage of the respondents know about cancer, their level of awareness for the need for cancer screening is still low. Education, access to healthcare facilities and socio-cultural factors still influenced the likelihood of the people to go for cancer screening and get cancer treatment. Therefore, health information and communication and cancer screening awareness campaign should be intensified to reach the public especially to the rural population. These efforts and initiatives can increase public access to information about cancer, and cancer screening and treatment facilities among the rural population, and especially those belonging to high-risk groups.
\end{abstract}

Keywords: cancer, cancer screening, health awareness, urban, rural, Malaysia

\section{Introduction}

Cancer is dangerous and refers to the diseases that happen as a result of abnormal growth and division of cells. There are several types of cancers, the most common types affecting men are lung, stomach, liver, colon, rectum, oesophagus and prostate cancer, while those commonly affecting women include breast, lung, stomach, colon, rectum and cervical cancer (WHO, 2009). Cancer is one of the leading causes of death in developed countries and the second leading cause of death in developing countries. However, out of 12.7 million cancer cases and 7.6 million cancer-related deaths in 2008, 56\% detected cases and $64 \%$ of the deaths occurred in developing countries (Jamel et al., 2011). Global cancer statistics show that developing countries have rising cancer-related deaths, especially among breast and cervical cancer cases. This is attributed to the low or lack of cancer awareness among the population (Okobia et al., 2006; Bhurgri et al., 2008) and delayed cancer screening and detection (Wong et al., 2009; Norsa'adah et al., 2011). Increasing cancer cases in developing countries is also linked to the ageing population, obesity rate, family history, and lifestyle choices such as smoking, unhealthy diet and lack of physical activities (Norsa'adah et al., 2005; Ghazali et al., 2009).

The awareness of the dangers of cancer and the importance of screening and early detection can reduce the risk of cancer mortality (CDC, 2004). According to the National Cancer Society (2006), 80\% of cancer cases can be treated if detected early. However, in developing countries like Malaysia, cancer cases are mainly detected at later or advanced stages (stages III or IV) (Ghazali et al., 2009). Detection at advanced stages can complicate patients' treatment, recovery and survival (Okobia et al., 2006; Wong et al., 2009). Late detection of the disease may be due to limited knowledge and awareness of the dangers of the disease. Apart from that, poverty, location factor and access to healthcare facilities also contribute to delayed screening, detection and treatment of cancer (Ghazali et al., 2009). 
Given the low survival rate of cancer of advanced stages, the knowledge and awareness of cancer and cancer screening are extremely important (Okobia et al., 2006; Bhurgri et al, 2008; Rabeta Mohd Salleh et al., 2011). Delayed cancer screening, detection, and treatment still occur even though there are initiatives by the government to raise public awareness of cancer. For example, in Malaysia, the number of women who actually go for pap smear tests remain low despite its introduction to the country in 1969 (Wong et al., 2009). Most of the women with cervical cancer cases receiving treatments in hospitals are also in the advanced stage. This ultimately contributes to higher cancer mortality in developing countries compared to developed countries (Okobia et al., 2006; Jamel et al., 2011).

Given that an increase number of cancer incidents and the problem of detecting cancer at late stage, awareness towards early screening is important. This study aimed to investigate awareness and knowledge of cancer among community in the state of Kedah and Perlis in Peninsular Malaysia.

\section{Background of the Study}

Diffussion of Innovation Theory has often been used to describe adoption of technology, ideas or innovations within the society. This theory predicts that media and interpersonal contacts provide information and influence opinion and judgement (Rogers, 1995). The information flows through networks such that the nature of networks and the presenters play significant role in ensuring the likelihood that the information will be trusted and adopted. In the context of disseminating health information, the medium used and the presenters of information and relationship that condition communication and learning would have great influence on creating public awareness and potentially acting upon them (Chamber et al., 2012). The study by Freedman et al (2011) among low-literate group found that health information could effective be disseminated through adult education health literacy class. The study involved 21 students and 3 teachers in an adult education health literacy class found that students have motivation to share health information with their classmates, their friends and family outside the classroom. The usage of information, communication technology (ICT) or social network also would probably be an effective mean of disseminating health information to the public.

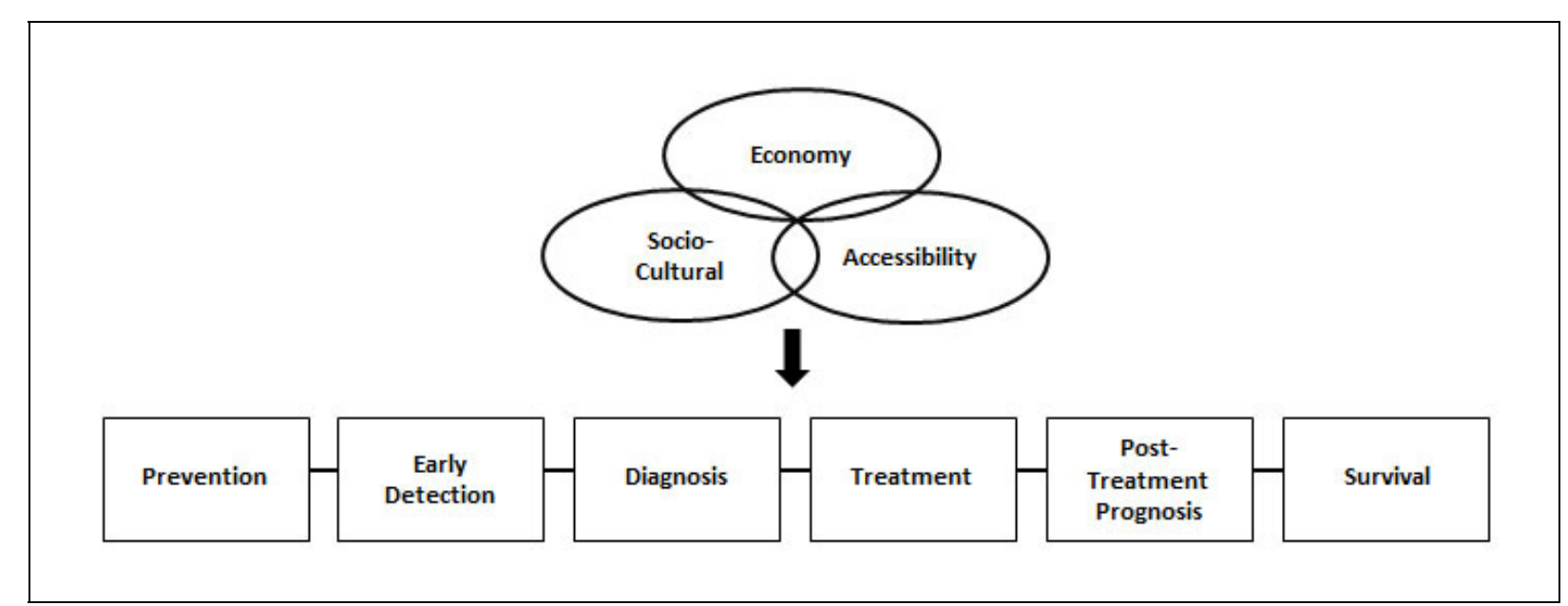

Figure 1. Financial and socio-cultural factors, and access to healthcare facilities and the cancer prevention, screening, treatment and survival

Source: Freeman (1991) cited from Ghazali, et al. (2009)

In addition to health information, accessibility to health care and screening centres are also important. Access to cancer screening, detection and treatment facilties, as well as social support are extremely important to facilitate high-risk individuals to go for screening tests and receive appropriate treatments. However, according to Lyons (2004), the number hospitals in rural areas that are equipped with cancer screening and treatment facilities is insufficient, contributing to delays in treatments urgently needed by patients already diagnosed with cancer. In reality, modern cancer treatment centres are primarily located in certain areas, particularly in urban areas and city centres and in areas with public amenities (Ghazali et al., 2009; Samat \& Abd Shattar, 2013). Samat et al. (2010) showed that hospitals with cancer treatment facilities are located in major cities in Penang and that several areas in the state such as Tasek Gelugor and Balik Pulau have low access to comprehensive healthcare and medical facilities. Longer distance from healthcare facilities and insufficient and ineffective public 
transportation system do not make access to healthcare facilities any easier for the rural population (Philips, 1990). Ghazali, et al., (2009) showed that 18 patients (6.1\%) in the northern region of Peninsular Malaysia travelled more than $200 \mathrm{~km}$ to and from hospitals for cancer treatments because the only hospital with comprehensive cancer treatment facilities is located in Penang Island. The international recommended travel distance from patient's home to hospital should be approximately $12 \mathrm{~km}$ or 20 minutes journey (in medium speed) (Jordon et al, 2004). This is to reduce patient's burden in terms of travel cost and pain during the journey.

Apart from healthcare access, financial and socio-cultural factors also influence cancer screening, and patients' treatment, recovery and survival (Freeman, 1999 cited from Ghazali, 2009). Figure 1 illustrates this relationship. Cancer patients face heavy financial stress due to high treatment cost. Cancer treatments may also make patients deem unfit to work and this can lead to loss of jobs and income (Ghazali et al., 2009; Yen Siew Hwa et al., 2011). Therefore, solid financial status, access to healthcare facilities, and conducive socio-cultural factors can increase the likelihood of patients to go for cancer screening and receive appropriate post-diagnosis treatment. Alternative treatments also contribute to delay post-diagnosis medical treatments in Malaysia (Norsa'adah et al., 2011).

Education is important in raising cancer awareness. In a research conducted in Nigeria, Okobia et al. (2006) discovered that lack of knowledge about breast cancer causes delayed cancer screening and treatment among suburban Nigerian women. The research also showed that the women's knowledge of breast cancer was low with only $21.4 \%$ of them knew that breast cancer can be detected from an unpainful lump in the breast. Educated and working women were also found to have higher knowledge of breast cancer. Bhurgi, et al. (2008) examined the level of awareness and knowledge of cancer risk factors among patients in Karachi, Pakistan. All 315 respondents have heard of cancer but knowledge that old age and obesity as cancer risk factors was still low. Rabeta Mohd Salleh, et al. (2011) asked 70 recently diagnosed breast cancer patients and found that the women's knowledge of breast cancer risk factors and lifestyle choices were still low. Wong, et al., (2009) studied the level of cervical cancer awareness of 20 women who have never had pap smear tests. Findings show that the women are unaware of the preventive measures of cervical cancer and only a small number of them knew that early detection can improve survival rates. Norsa'dah, et al. (2011) showed that most breast cancer patients in Malaysia were diagnosed at later or advanced stages. This is in contrast to the early detected cancer cases in the Western nations. For example, Gunfeld, et al. (2002) discovered that $90 \%$ of British women can identify family history as a cancer risk factor. The study also showed that $70 \%$ of British women knew that a lump in the breast or under the armpit can be a symptom of breast cancer. These findings demonstrate that the level of cancer knowledge and awareness of cancer screening in developing countries are still low.

Cancers diagnosed at later or advanced stages is one of the leading causes of the increasing number of cancer-related deaths in developing countries (Wong, et al., 2009; Jamel, et al., 2011; Norsa'adah, et al., 2011). Therefore, education and knowledge of cancer risk factors and healthy lifestyle choices are crucial in decreasing cancer risks and mortality. Awareness of the importance of consistent cancer screening especially among those within the high-risk groups are also important so that people are aware of the need for medical examinations even though during their healthy years (Wong, et al., 2009; Rabeta Mohd Salleh, et al., 2011). Cancer knowledge and awareness among the public are therefore, extremely important (Lahijanian, 2011).

The rural population finds hospital visits are not worth going because of limited or lack of knowledge about cancer and general health and wellbeing. According to Phillips (1990) and Gary, et al. (2005), medical treatments are inaccessible to the rural population because of high travelling and treatment costs. Ghazali, et al. (2009) interviewed 295 cancer patients and found that 48 of them (16.3\%) were diagnosed at stage IV, 125 $(42.2 \%)$ at stage III, $113(38.3 \%)$ at stage II and only $9(3.0 \%)$ at stage I. This shows that most cancer cases were detected late. Locations of hospitals, primarily in the main cities, also do not make it easy for the rural folks to get treatments. Challenges such as alternative cancer treatments, costs of treatment and travelling, time factor and low level of awareness about the early symptoms of cancer contribute to late detection, diagnosis and treatment (Norsa'adah et al., 2011).

Location of hospitals influences public access (or lack thereof) of health information and cancer screening and treatment facilities. In the northern region of Peninsular Malaysia, the Penang Public Hospital provides comprehensive cancer treatments to patients within the area. However, patients in the states of Perlis and Kedah need to travel more than $200 \mathrm{~km}$ to receive cancer treatments in Penang Hospital. For this reason, this study examines the relationship between residential location and cancer knowledge and awareness among the general public in Kedah and Perlis. This study also examines the relationship between education level and residential location with the awareness and knowledge cancer and the need for cancer screening. 


\section{Methodology}

Respondents of this study are the general public residing in the states of Kedah and Perlis. The selected states were further categorized into urban (Alor Setar), suburban (Langgar and Kuala Kedah in Kedah and Beseri in Perlis) and rural (Baling in Kedah) areas. These locations were selected because of their large distance from cancer treatment centre, which is located in the Penang General Hospital. This study builds upon that by MAKNA that focused on cancer patients in the northern region. Random sampling method was employed and the final sample consists of 544 respondents who are over the age of 16. Data were gathered through personally-administered questionnaires and analyzed with Statistical Package for Social Sciences (SPSS), version 17. Descriptive statistics and cross tabulations analyses were conducted and presented.

\section{Demographic and Socio-cultural Profiles of Respondents}

From a total of 544 respondents, $221(40.6 \%)$ are males, while $323(59.4 \%)$ are females. Table 3 displays the respondents' demographic and socio-cultural profiles. Baling, Langgar and Beseri were represented by $17.6 \%$ or 143 respondents. Kuala Kedah and Alor Setar were each represented by $23.5 \%$ or 128 respondents. The majority of the respondents ( 143 or $26.3 \%$ ) belong to the 16 to 25 years old age group, and this is followed by those between 46 to 55 years old ( 98 respondents or 18\%), between 26 to 35 years old ( 92 or 16.9\%), between 36 to 45 years old (83 respondents or 15.3\%), between 56 to 65 years old (79 or 14.5\%) and 66 years and older (49 respondents or $9.0 \%)$. The majority ( 420 or $77.2 \%$ ) of the respondents hail from the rural and suburban areas, while $22.8 \%$ of the respondents (540) are from the urban area (Alor Setar).

The majority of the respondents have some form of formal education and only $5.9 \%$ (32 respondents) have no formal education. Table 3 displays respondents' level of education according to their residential location. A little under half $(45.2 \%)$ or 246 of the respondents have upper secondary education, $20 \%$ or 109 have primary education, $15.6 \%$ or 85 respondents have tertiary education, and $13.2 \%$ or 72 respondents have lower secondary education. Overall, the respondents of this study are quite educated and able to understand and provide responses to the questions in the questionnaire.

Table 1. Respondents' demographic and socio-cultural profiles

\begin{tabular}{ccc}
\hline Gender & Frequency $(\mathrm{n}=544)$ & Percentage (100) \\
\hline Male & 32 & 5.9 \\
Female & 109 & 20.0 \\
\hline Location & Frequency $(\mathrm{n}=544)$ & Percentage (100) \\
\hline Baling & 96 & 17.6 \\
Kuala Kedah & 128 & 23.5 \\
Alor Setar & 128 & 23.5 \\
Langgar & 96 & 17.6 \\
Beseri & 96 & 17.6 \\
\hline Age group & Frequency $(\mathrm{n}=544)$ & Percentage (100) \\
\hline 25 and below & 143 & 26.3 \\
26 to 35 & 92 & 16.9 \\
36 to 45 & 83 & 15.3 \\
46 to 55 & 98 & 18.0 \\
56 to 65 & 79 & 14.5 \\
65 and older & 49 & 9.0 \\
\hline Education level & 32 & Percentage (100) \\
\hline No formal education & 109 & 5.9 \\
Primary education & 72 & 20.0 \\
Lower secondary education & 246 & 13.2 \\
Higher secondary education & 85 & 45.2 \\
Tertiary education & Frequency $(\mathrm{n}=544)$ & 15.6 \\
\hline
\end{tabular}

\section{Knowledge and Awareness of Cancer}

Knowledge and awareness of cancer is extremely important to effectively detect and treat the disease. Thus, this study examines whether the respondents in the selected locations have awareness and knowledge of cancer. This study also examines respondents' knowledge of cancer and and cancer screening. Findings reveal that 96\% (522 
respondents) have heard of cancer and have some knowledge about it. Respondents know that cancer is dangerous and can be fatal, and its cure and treatment are difficult. Only $4 \%$ (22) of the respondents have never heard of cancer. More respondents from the urban areas were found to have knowledge of cancer compared to those from other areas. Table 4 shows that $97.6 \%$ (121) of the urban respondents have heard of cancer, and only $3.0 \%$ (3) have never heard of it. The percentage of the rural respondents who have heard of cancer is slightly lower than that of the urban respondents. That is, $95.5 \%$ (401 respondents) have heard of cancer and $4.5 \%$ (19 respondents) have never heard of cancer are from the rural areas. Even though the percentage of those who have not heard of cancer is small, it still needs to be highlighted to ensure that public awareness of cancer is widespread.

Table 2. Relationship between location and awareness of cancer

\begin{tabular}{ccccccc}
\hline \multirow{2}{*}{ Awareness of cancer } & \multicolumn{2}{c}{ Urban } & \multicolumn{2}{c}{ Rural } & \multicolumn{2}{c}{ Total } \\
\cline { 2 - 7 } & No & $\%$ & No & $\%$ & No & $\%$ \\
\hline Heard of cancer & 121 & 97.6 & 401 & 95.5 & 522 & 96.0 \\
Have not heard of cancer & 3 & 3.0 & 19 & 4.5 & 22 & 4.0 \\
Total & 124 & 100.0 & 420 & 100.0 & 544 & 100.0 \\
\hline
\end{tabular}

This study also examines the relationship between respondents' awareness and knowledge of cancer and their level of education. Findings in Table 5 are consistent with Okobia, et al. (2006), who found that those who have not heard of cancer have either no formal education or have primary education. Education is important in raising knowledge and awareness of cancer. A small number (6) of respondents who have upper secondary education have never heard of cancer. This is rather worrying as secondary school students are expected to know about cancer. Respondents' relaxed attitude towards health and symptoms of health problems may contribute to the lack of knowledge about cancer (Ghazali et al., 2009).

Table 3: Relationship between education level and awareness ledge of cancer

\begin{tabular}{ccccccc}
\hline \multirow{2}{*}{ Education level } & \multicolumn{3}{c}{ Heard of cancer } & \multirow{2}{*}{ Total } \\
\cline { 2 - 6 } & \multicolumn{2}{c}{ Yes } & No & \multirow{2}{*}{$\%$} \\
\cline { 2 - 6 } & No. & $\%$ & No. & $\%$ & & \\
\hline No formal education & 24 & 75.0 & 8 & 25.0 & 32 & 100 \\
Primary education & 101 & 92.7 & 8 & 7.3 & 109 & 100 \\
Lower secondary education & 72 & 100.0 & 0 & 0.0 & 72 & 100 \\
Upper secondary education & 240 & 97.6 & 6 & 2.4 & 246 & 100 \\
Tertiary education & 85 & 100 & 0 & 0.0 & 85 & 100 \\
Total & 522 & 100.0 & 22 & 100.0 & 544 & 100 \\
\hline
\end{tabular}

Table 4. Relationship between location and knowledge of cancer risk factors

\begin{tabular}{ccccccc}
\hline Knowledge of & \multicolumn{5}{c}{ Location } & \multirow{2}{*}{ Total } \\
\cline { 2 - 5 } cancer risk factors & Baling & Kuala Kedah & Bandar Alor Setar & Langgar & Beseri & \\
\hline \multirow{2}{*}{ Yes } & 57 & 84 & 95 & 61 & 71 & 368 \\
& $59.4 \%$ & $65.6 \%$ & $74.2 \%$ & $63.5 \%$ & $74.0 \%$ & $67.6 \%$ \\
No & 39 & 44 & 33 & 35 & 25 & 176 \\
& $40.6 \%$ & $34.4 \%$ & $36.5 \%$ & $36.5 \%$ & $26.0 \%$ & $32.4 \%$ \\
\multirow{2}{*}{ Total } & 96 & 128 & 96 & 96 & 96 & 544 \\
& $100 \%$ & $100 \%$ & $100 \%$ & $100 \%$ & $100 \%$ & $100 \%$ \\
\hline
\end{tabular}

Next, this study examines respondents' knowledge of cancer risk factors. Table 6 shows that $67.6 \%$ (368) of respondents have knowledge of cancer and cancer risk factors, while $32.4 \%$ (176) have no clue about cancer risk factors. Respondents' location is found to influence knowledge of cancer. The percentage of urban respondents who have knowledge of cancer is higher than those of suburban and rural respondents. Table 5 shows that $75 \%$ (93) of urban respodents have knowledge of cancer risk factors while only $25 \%$ (31) do not. The percentage of rural respondents who have no knowledge of cancer risk factors is higher than that of urban respondents. More 
than half $(56.1 \%$ or 83$)$ of the respondents have knowledge of cancer risk factors compared to $43.9 \%$ who do not. Similar findings were discussed in Phillips (1990) and Gary, et al. (2005) who found respondents' location to influence knowledge of cancer.

This study also examines the relationship between respondents' education level and knowledge of cancer risk factors. The percentage of respondents who have tertiary education and knowledge of cancer risk factors is high at $90.6 \%$ (77 respondents), and only 9.4\% (8 respondents) of them have no knowledge of cancer risk factors. The percentage of respondents who do not have formal education and have knowledge of cancer risk factors is low at $28.1 \%$ ( 9 respondents), compared to $71.9 \%$ (23 respondents) who do not have knowledge of cancer risk factors. The findings support Bhugri et al. (2008) and Okobia, et al. (2006). Cancer risk factors stated by respondents are categorized into four namely food, family history or genetics, lifestyle and the environment as cancer risk factors (Ghazali et al., 2009). 44.1\% of respondents stated that food such as instant noodles and fizzy drinks increase the risk of cancers, while $38.8 \%$ felt that unhealthy lifestyles such as lack of physical exercise and smoking contribute to cancer. Only $14.6 \%$ and $4.5 \%$ of respondents stated family history (genetics) and the environment such as toxic polution, respectively, to be cancer risk factors (Table 8). Findings show that 356 respondents have quite a bit of knowledge about cancer risk factors.

Table 5. Relationship between education level and knowledge of cancer risk factors

\begin{tabular}{|c|c|c|c|c|c|c|}
\hline \multirow{3}{*}{ Education level } & \multicolumn{4}{|c|}{ Knowledge of cancer risk factors } & \multicolumn{2}{|c|}{ Total } \\
\hline & \multicolumn{2}{|c|}{ Yes } & \multicolumn{2}{|c|}{ No } & \multirow{2}{*}{ No. } & \multirow{2}{*}{$\%$} \\
\hline & No. & $\%$ & No. & $\%$ & & \\
\hline No formal education & 9 & 28.1 & 23 & 71.9 & 32 & 100 \\
\hline Primary education & 55 & 50.5 & 54 & 49.5 & 109 & 100 \\
\hline Lower secondary education & 45 & 62.5 & 27 & 37.5 & 72 & 100 \\
\hline Upper secondary education & 182 & 74.0 & 64 & 26.0 & 246 & 100 \\
\hline Tertiary education & 77 & 90.6 & 8 & 9.4 & 85 & 100 \\
\hline Total & 368 & 67.6 & 176 & 32.4 & 544 & 100 \\
\hline
\end{tabular}

Table 6. Respondents' knowledge of cancer risk factors according to gender

\begin{tabular}{lccccccc}
\hline \multirow{2}{*}{ Cancer risk factors } & \multicolumn{2}{c}{ Male } & \multicolumn{2}{c}{ Gender } & \multicolumn{2}{c}{ Female } & \multicolumn{2}{c}{ Total } \\
\cline { 2 - 5 } \cline { 5 - 6 } & No. & $\%$ & No. & $\%$ & No. & $\%$ \\
\hline Food & 67 & 40.8 & 90 & 46.9 & 157 & 100 \\
Family history (genetics) & 17 & 10.4 & 35 & 18.2 & 52 & 100 \\
Lifestyle & 73 & 44.5 & 58 & 30.2 & 131 & 100 \\
Environment & 7 & 4.3 & 9 & 4.7 & 16 & 100 \\
Total & 164 & 100.0 & 192 & 100.0 & 356 & 100 \\
\hline
\end{tabular}

Knowledge and awareness of cancer alone is insufficient. People who are aware and have knowledge of cancer should take pro-active actions by going for cancer screening. Cancer screening is important for early detection of cancer (Wong et al., 2009). Therefore, this study examines the relationship between respondents' knowledge of cancer and cancer screening. Findings show that $69.5 \%$ (378) of the respondents have heard of cancer screening compared to $30.5 \%$ (166) who have not. However, the percentage of respondents who have gone for cancer treatment is still low. Only 187 respondents or $36.2 \%$ have actually gone for cancer screening. The percentage of respondents who have gone for cancer screening is low. Only 197 respondents $(36.2 \%)$ have gone for cancer screening compared to 347 respondents $(63.8 \%)$ who have not. The percentage of female respondents who have gone for cancer screening is higher. $44.3 \%$ or 143 female respondents have gone for cancer screening compared to $24.4 \%$ or 54 males who have not. Even though many respondents possess knowledge of cancer, the number of those who have gone for cancer screening is still small. These findings emphasize the role of education in raising awareness and providing accurate information about cancer and the need for cancer screening (Wong et al., 2009; Lahijanian, 2011).

Education influences cancer screening. Findings show that the percentage of respondents who have gone for cancer screening is low among those with no formal education. Table 9 shows that only $18.8 \%$ or 6 respondents with no formal education have gone for cancer screening. However, the percentage of respondents who have 
formal education and have gone for cancer screening is also low. Findings also show that while respondents may have knowledge of cancer, they do not necessarily see the need to go for cancer screening. This may be because they do not see the need to go for cancer screening when they are in good health conditions (Wong et al., 2009). Cancer screening campaigns should be emphasized to raise public awareness of the importance of cancer screening and early detection of cancer.

Table 7. Respondents who have gone for cancer screening according to education level

\begin{tabular}{lccccccc}
\hline Education level & \multicolumn{3}{c}{ Cancer screening } & & \multicolumn{2}{c}{ Total } \\
\cline { 2 - 5 } \cline { 5 - 6 } & No. & $\%$ & No. & & \multirow{2}{*}{ No. } & \multirow{2}{*}{$\%$} \\
\hline No formal education & 6 & 18.8 & 26 & 81.2 & 32 & 100 \\
Primary education & 52 & 47.7 & 57 & 52.3 & 109 & 100 \\
Lower secondary education & 27 & 37.5 & 45 & 62.5 & 72 & 100 \\
Upper secondary education & 85 & 34.6 & 161 & 65.4 & 246 & 100 \\
Tertiary education & 27 & 31.8 & 58 & 68.2 & 85 & 100 \\
Total & 197 & 36.2 & 347 & 63.8 & 544 & 100 \\
\hline
\end{tabular}

\section{Discussion}

The increasing incidences of cancer incidences and mortality are extremely worrying. This increase is more prevalent in developing countries compared to developed countries (Jamel, et al., 2011). This is because of early cancer detection in developed countries. In developing countries, cancer cases are detected and diagnosed at stages III and IV, which contribute to issues and challenges in treatments, recovery and survival (Rabeta Mohd Salleh, et al., 2010). Preventive measures and effective treatment can only be achieved with early detection and appropriate treatments. There is an urgent need to set up initiatives and efforts to disseminate accurate and timely cancer information especially about common cancers such as breast, cervical, colon, rectum, lung and prostate cancer. Breast cancer and cervical cancer are two of the most common cancers affecting women. However, screening for these types of cancer among women is still low. The number of women who actually go for pap smear tests is still low even though the tests were introduced in 1969 (Wong et al., 2009).

Public awareness on the importance of cancer screening can be achieved by creating and raising awareness of cancer and general and health wellbeing according to age and environmental factors. Campaigns and efforts to raise awareness and to educate the population on basic information about cancer should start early. Organizations such as the Ministry of Health Malaysia, the National Cancer Council (MAKNA) and the National Cancer Society should broaden their initiatives to raise cancer awareness to primary and secondary school students. Age appropriate cancer information can raise cancer awareness amongst the younger generation without terrifying them (Ghazali et al., 2009). The usage of social network could potentially be explored in effort to reach wider coverages.

Cancer information should also be tailored to the mentalities of the rural and urban population as well as those with low and high level of education. Information related to healthy diet and lifestyle choices should also be tailored according to the environment and population's education level. For example, the usage of social network could be used to reach young generation. This is to ensure that information and knowledge about cancer are understood by all groups of people within the society and that the issue of culturally- and religiously-sensitive information about cancer is addressed. Rural clinics also should be a distribution channel of for information and knowledge about cancer as they are the nearest medical centres especially to the rural population. The circulation of cancer information through the mass and other forms of media should be intensified to raise the level of cancer awareness and the importance of cancer screening among the general public, especially those who belong to high-risk groups (Okobia et al., 2006; Ghazali et al., 2009). This can also be done by providing screening facilities in strategic locations, especially in rural areas (Samat et al., 2010) and setting up health campaigns to educate and provide early exposure of cancer to everybody (Lahijanian, 2011). Other than that, the need for cancer screening should be emphasized as early as in primary schools so that more people from all walks of life have awareness and knowledge of cancer.

\section{Conclusion}

Overall, the awareness and knowledge of cancer screening among the general public is still low. However, those who live in urban areas and possess higher education level are more likely to go for cancer screening. Therefore, 
prevention and control measures should be intensified especially in raising awareness through of the importance of living healthy lifestyles, especially among the rural population. Information related to healthcare, cancer screening, treatment, healthy food and healthy lifestyle choices should be emphazised at all levels of the society.

\section{Acknowledgements}

Authors would like to thank Universiti Sains Malaysia for funding this project through Research Collaboration between MAKNA-USM, and Research University Team Grant, 1001/PHUMANITI/856002, Geography Fieldwork Students for helping in gathering data used in the study and all respondents for taking time to answer the questionnaires.

\section{References}

Bhurgru, H., Gowani, S. A., Itrat, A., Samani, S., Zuberi, A., Siddique, M. S., .. Bhurgri, Y. (2008). Awareness of cancer risk factors among patients and attendants presenting to a Tertiary Care Hospital in Karachi, Pakistan. Journal of Pakistan Medical Association, 58(10), 584-588.

CDC. (2004). The national breast and cervical cancerearly detection program-reducing mortality through screening, Cancer Prevention and Control, National Centre for Chronic Disease Prevention and Health Promotion. Retrieved from http://www.cdc.gov/cancer/nbccedp/about.htm

Chamber, D., Wilson, P., Thompson, C., \& Harden, M. (2012). Social Network Analysis in Healthcare Settings: A Systematic Scoping Review. PLoS ONE, 7(8), e41911. http://dx.doi.org/10.1371/journal.pone.0041911

Freedman, A. M., Miner, K. R., Echt, K. V., Parker, R., \& Cooper, H. L. (2011). Amplifying diffusion of health information in low-literate populations through adult education health literacy classes. Journal of Health Communication: International Perspectives, 16(sup3), 119-133.

Gary, D., Shaw, J., \& Farrington, J. (2006). Community transport, social capital and social exclusion in rural areas. Areas, 38(1), 89-98. http://dx.doi.org/10.1111/j.1475-4762.2006.00662.x

Ghazali, S., Atang, C., Samat, N., Md Nor, Norizan, A., Azlinda, H., Hashimah, I., \& Mokhtar, K. (2009). Kesengsaraan Berganda - Kemiskinan dan Kanser: Satu Tinjauan ke Arah Tindakan. Laporan Akhir Penyelidikan Usahasama Majlis Kanser Nasional - Universiti Sains Malaysia. Jun.

Hwa, Y. S., Abd Shattar, A. K., \& Hashim, H. (2011). The socio-economic impacts of breast cancer on breast cancer patients in Penang. Kajian Malaysia, 29(2), 111-136.

Jamel, A., Bray, F., Center, M. M., Ferlay, J., Ward, E., \& Forman, D. (2011). Global cancer statistics. CA Cancer J Clin, 61, 69-90. http://dx.doi.org/10.3322/caac.20107

Jordon, H., Roderick, P., Martin, D., \& Barnett, S. (2004). Distance, rurality and the need for health care: Access to health services in South West England. International Journal of Health Geographics, 3(21). Retrieved August 8, 2006, from http://www.ij-healthgeographicls.com/content/3/1/21

Lahijanian, A. (2011). Public Participation in environmental education centers. International Journal of Environmental Research, 5(4), 951-960.

Lim, C. C. G., \& Yahaya, H. (2004). Second Report of the National Cancer Registry Cancer Incidence in Malaysia 2003. National Cancer Registry. Ministry of Health Malaysia.

Lim, C. C. G., Yahaya, H., \& Lim, T. O. (2003). The First Report of the National Cancer Registry Cancer Incidence in Malaysia 2002. National Cancer Registry. Ministry of Health Malaysia.

Lyons, M. (2004). Psychosocial impact of cancer in low-income rural/urban women: Phase I. Online Journal of Nursing and Health Care, 41(1). Retrieved from http://www.rno.org/journal/issues/Vol-4/issue-1/ Lyons_article.htm

Norsa'adah, B., Rampal, K. G., Rahmah, M. A., Naing, N. N., \& Biswal, B. M. (2011). Diagnosis delay of breast cancer and its associated factors in Malaysian women. BMC Cancer, 11, 141, http://dx.doi.org/10.1186/1471-2407-11-141

Norsa'adah, B., Rusli, B. N., Imran, A. K., Naing, I., \& Winn, T. (2005). Risk factors of breast cancer in women in Kelantan, Malaysia. Singapore Medical Journal, 46(12), 698-705.

Okobia, M. N., Bunker, C. H., Okonofua, F. E., \& Osime, U. (2006). Knowlegde, attitude and practice of Nigerian women towards breast cancer: A cross-sectional study. World Journal of Surgical Oncology, 4(11). http://dx.doi.org/10.1186/1477-7819-4-11.

Philips, W. J. (1990). Health and Health Care in the Third World. New York: John Wiley \& Sons. 
Rogers, E. M. (1995). Diffusion of innovations (4th ed.). New York: The Free Press.

Salleh, R. M., Shahar, S., Ghazali, A. R., Haron, N., \& Koon, P. B. (2011). Risk factor for breast cancer among women in Klang Valley, Malaysia. Health and the Environment Journal, 2(2), 29-33.

Samat, N., \& Shattar, A. K. A. (2013). Spatial Accessibility of Cancer Patients to Health Facilities: An Example for Breast and Cancer Incidents in Kelantan State, Malaysia. In N. Samat, Z. A. Rahaman, S. R. S. Dawood, W. R. Ismail, \& R. Rainis (Eds.), Selected Issues on Health and Environment (pp. 9-18). Universiti Pendidikan Sultan Idris.

Samat, N., Shatar, A. K. A., Jambi, D., Manan, N. M. A. A., \& Sulaiman, Y. (2010). Using Geographic Information System in evaluating accessibility of Breast Cancer cases to health facilities in Penang State, Malaysia. Kajian Malaysia-Journal of Malaysian Studies, 28(1), 103-122.

WHO. (2009). Cancer. Retrieved from http://www.who.int/mediacentre/factsheets/fs297/en/index.html.

Wong, L. P., Wong, Y. L., Low, W. Y., Khoo, E. M., \& Shuib, R. (2009). Knowledge and awareness of cervical cancer and screening among Malaysian women who have never had a Pap smear: A qualitative study. Singapore Medical Journal, 50(1), 49-53.

\section{Copyrights}

Copyright for this article is retained by the author(s), with first publication rights granted to the journal.

This is an open-access article distributed under the terms and conditions of the Creative Commons Attribution license (http://creativecommons.org/licenses/by/3.0/). 